\title{
Papers
}

\section{Percutaneous transluminal coronary angioplasty versus medical treatment for non-acute coronary heart disease: meta-analysis of randomised controlled trials}

\author{
Heiner C Bucher, Peter Hengstler, Christian Schindler, Gordon H Guyatt
}

\begin{abstract}
Objective To determine whether percutaneous transluminal coronary angioplasty (angioplasty) is superior to medical treatment in non-acute coronary artery disease.

Design Meta-analysis of randomised controlled trials. Setting Randomised controlled trials conducted worldwide and published between 1979 and 1998. Participants 953 patients treated with angioplasty and 951 with medical treatment from six randomised controlled trials, three of which included patients with multivessel disease and pre-existing myocardial infarction.

Main outcome measures Angina, fatal and non-fatal myocardial infarction, death, repeated angioplasty, and coronary artery bypass grafting.

Results In patients treated with angioplasty compared with medical treatment the risk ratios were $0.70(95 \%$ confidence interval 0.50 to 0.98 ; heterogeneity $\mathrm{P}<0.001)$ for angina; 1.42 (0.90 to 2.25) for fatal and non-fatal myocardial infarction, 1.32 (0.65 to 2.70$)$ for death, 1.59 (1.09 to 2.32) for coronary artery bypass graft, and 1.29 ( 0.71 to 3.36 ; heterogeneity $\mathrm{P}<0.001$ ) for repeated angioplasty. Differences in the methodological quality of the trials, in follow up, or in single versus multivessel disease did not explain the variability in study results in any analysis.

Conclusions Percutaneous transluminal coronary angioplasty may lead to a greater reduction in angina in patients with coronary heart disease than medical treatment but at the cost of more coronary artery bypass grafting. Trials have not included enough patients for informative estimates of the effect of angioplasty on myocardial infarction, death, or subsequent revascularisation, though trends so far do not favour angioplasty.
\end{abstract}

\section{Introduction}

In the past decade highly industrialised countries have seen an enormous increase in the use of percutaneous transluminal coronary angioplasty for the treatment of coronary heart disease. ${ }^{12}$ Randomised controlled trials and systematic reviews have explored the effectiveness of angioplasty in acute coronary heart disease as an alternative treatment to thrombolysis ${ }^{3}$ or as an adjuvant to thrombolysis at different times during early treatment after myocardial infarction. ${ }^{45}$ Primary percutaneous transluminal coronary angioplasty may be superior to thrombolysis in selected patients with acute myocardial infarction, ${ }^{3}$ but the use of this treatment after thrombolysis in acute myocardial infarction has shown conflicting results with questionable benefit. ${ }^{45}$ In chronic coronary heart disease, several randomised trials have compared percutaneous transluminal coronary angioplasty with coronary artery bypass grafting. ${ }^{6}$ Fewer investigations, however, have explored its effectiveness compared with medical treatment in the management of non-acute coronary heart disease.

The choice of continued medical treatment versus percutaneous transluminal coronary angioplasty remains relevant for patients with limited coronary disease and good myocardial function. When resources limit access to angiography, the magnitude of benefit with angioplasty becomes an important issue. We therefore conducted a meta-analysis of randomised controlled trials that compared percutaneous transluminal coronary angioplasty with medical treatment in non-acute coronary heart disease. We summarised results from individual small trials, investigated whether angioplasty in patients with non-acute coronary heart disease reduces angina, myocardial infarction, death, and revascularisation, and summarised the magnitude of the effects on each outcome.

\section{Methods}

We searched Medline, Embase, Cochrane database, Biological Abstracts, Health Periodicals Database, and PASCAL from 1979 through December 1998 using the following MeSH terms: transluminal percutaneous coronary angioplasty, cardiovascular agents, coronary disease, and the truncated textword random. The search identified 875 references, and an additional 705 references were reviewed in the Cochrane database by using the MeSH term transluminal percutaneous coronary angioplasty. We also examined the citations from relevant articles and previous overviews. We included only those studies that met the following criteria: random allocation of patient to treatment; comparison of percutaneous transluminal coronary angioplasty with medical treatment (for instance,

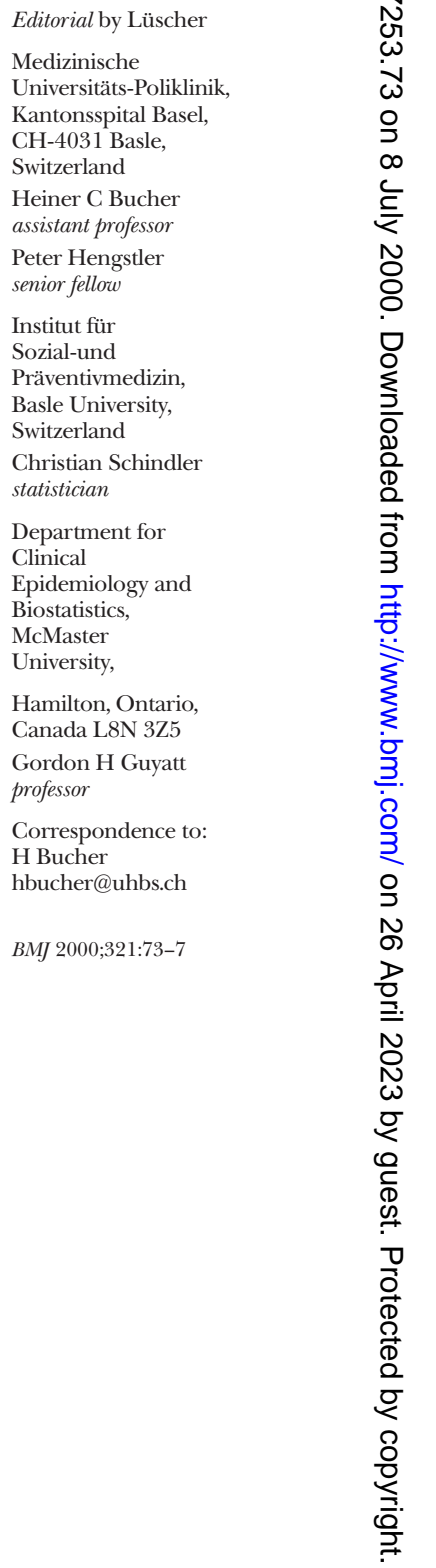


anti-ischaemic treatment and treatment of risk factors for secondary events); and patients had to have non-acute coronary heart disease with no acute myocardial infarction for at least one week before randomisation. Two investigators ( $\mathrm{HCB}$ and $\mathrm{PH}$ ) independently assessed study eligibility ( $\kappa$ for agreement for eligibility 0.91 ).

Presence of angina at the end of the study, non-fatal myocardial infarction, death, need for re-angioplasty, and coronary artery bypass grafting were the end points. For angioplasty we compared the rates of additional angioplasties in the invasive groups from each trial with the rates of percutaneous transluminal coronary angioplasty in the medically treated groups. We additionally looked at the improvement of exercise time during exercise testing and the mean change in angina, but inconsistent reporting of these end points precluded analysis. We assessed the quality of included trials using a modified version of the score used by Jadad et al. ${ }^{8}$ We rated the methodological quality of the included trials based on randomisation of participants, blinding of patients, caregivers, and those assessing outcome, and full description of withdrawals and dropouts. The scoring gives one point to each item if present. If randomisation is concealed (central allocation) and if the method of double blinding is appropriate (identical placebo, active placebo, dummy, etc) the study receives one additional point, thus yielding a score with a range from 0 to 5 points.

To explore variability in study results (heterogeneity) we specified the following hypotheses before conducting the analysis. We hypothesised that effect size may differ according to the methodological quality of the studies, single versus multiple vessel angioplasty, and the duration of follow up. We tested the difference in combined estimates of subgroups using the $\mathrm{z}$ score for each type of subgroup by dividing the difference in the subgroup summary log relative risk by the standard error of the difference. Because risk ratios and risk differences provide complementary information we made calculations for both measures of association. For succinctness of presentation we present risk differ- ences only when we found significant differences between groups. We pooled data from individual trials using a random effect model ${ }^{9}$ and used the Breslow Day test to test for heterogeneity. ${ }^{10}$ We added 0.5 to all cells with no events. All analyses were done with SAS software (version 6.12, 1996).

\section{Results}

We identified 429 randomised controlled trials: 73 trials did not compare percutaneous transluminal coronary angioplasty with control, 312 trials evaluated various procedures related to angioplasty (for example, cotreatments and different techniques for the prevention of restenosis), eight trials compared angioplasty with coronary artery bypass grafting, and 28 trials included patients with acute coronary disease. Eight trials proved eligible, of which two had to be excluded because allocation to angioplasty in the intervention groups was not random. ${ }^{11}{ }^{12}$

Of the six remaining trials, three included patients with multivessel disease and pre-existing $Q$ wave myocardial infarction (table 1$)^{13-15}$ and three were restricted to single vessel disease and patients without previous $Q$ wave infarction. ${ }^{16-18}$ The success rates for percutaneous transluminal coronary angioplasty varied between $80 \%$ and $100 \%$. Rates of complications varied between $0.01 \%$ and $2.8 \%$ for myocardial infarction and between $1.5 \%$ and $2.8 \%$ for immediate coronary artery bypass grafting. There was one death related to percutaneous transluminal coronary angioplasty in one trial. ${ }^{14}$ Antithrombotic prophylaxis in the angioplasty study groups reflects practice at the time the studies were conducted. During percutaneous transluminal coronary angioplasty patients received only heparin, and stents were used in a minority of patients in only one study. ${ }^{14}$ In all trials medical treatment included administration of antiplatelet agents, $\beta$ blockers, nitrates, and calcium channel blockers, but only one trial used aggressive lipid lowering treatment. ${ }^{15}$ The mean follow up time in the 953 patients treated with angioplasty and 951 with medical treatment ranged between 6 and 57 months, and quality scores varied between 2 and 4

Table 1 Baseline characteristics and criteria for inclusion in randomised controlled trials of percutaneous transluminal coronary angioplasty (PCTA) compared with medical treatment in non-acute coronary heart disease

\begin{tabular}{|c|c|c|c|c|c|c|c|c|c|}
\hline \multirow[b]{2}{*}{ Study } & \multicolumn{2}{|c|}{ Inclusion criteria } & \multirow{2}{*}{$\begin{array}{l}\text { No of vessels } \\
\text { (\% successful } \\
\text { dilatation) }\end{array}$} & \multirow{2}{*}{$\begin{array}{l}\text { Complications } \\
\text { related to PTCA in } \\
\text { intervention groups }\end{array}$} & \multirow{2}{*}{$\begin{array}{l}\text { Follow up } \\
\text { (months) }\end{array}$} & \multicolumn{2}{|c|}{$\begin{array}{l}\text { Pre-existing } \\
\text { condition (\%) }\end{array}$} & \multirow{2}{*}{$\begin{array}{c}\text { Mean } \\
\text { ejection } \\
\text { fraction (\%) }\end{array}$} & \multirow{2}{*}{$\begin{array}{l}\text { Trial } \\
\text { quality } \\
\text { score }\end{array}$} \\
\hline & Clinical & Angiographic & & & & MI & Non-Q MI & & \\
\hline $\begin{array}{l}\text { Parisi } \\
1992^{17}\end{array}$ & $\begin{array}{l}\text { Stable angina, history of angina, MI } \\
\text { within } 3 \text { months, exercise test with ST } \\
\text { depression }>3 \text { mm, no previous PTCA }\end{array}$ & $\begin{array}{l}\text { Single or serial stenosis within same } \\
\text { artery } 70 \% \text { to } 99 \% \text { proximal two } \\
\text { thirds }\end{array}$ & $1(82)$ & $\begin{array}{c}\text { CABG }(2.0 \%) ; \mathrm{MI} \\
(1.0 \%) ; \text { non- } Q \text { wave } \\
\text { MI }(3.0 \%)\end{array}$ & 6 & 0 & 28.8 & 65 & 4 \\
\hline $\begin{array}{l}\text { Sievers } \\
1993^{16}\end{array}$ & $\begin{array}{l}\text { Previous non- } Q \text { wave } M l, \text { no angina in } \\
\text { daily life, no previous } Q \text { wave } M I\end{array}$ & $\begin{array}{l}\text { Mean (SD) degree of stenosis: } 86 \% \\
\text { (11) }\end{array}$ & $1(100)$ & None & 24 & 0 & 54.5 & NA & 2 \\
\hline $\begin{array}{l}\text { MASS } \\
1995^{18}\end{array}$ & $\begin{array}{l}\text { Stable angina, no } Q \text { wave } \mathrm{MI} \text {, no left } \\
\text { ventricular dysfunction }\end{array}$ & $\begin{array}{l}\text { Stenosis } \geqslant 80 \% \text { before first diagonal } \\
\text { branch, length }<12 \mathrm{~mm} \text {, no total } \\
\text { occluded lesion }\end{array}$ & $1(96)$ & $\begin{array}{c}\text { CABG }(2.8 \%) ; \mathrm{MI} \\
(2.8 \%)\end{array}$ & 30 & 0 & 0 & 76 & 3 \\
\hline $\begin{array}{c}\text { Folland } \\
1997^{13}\end{array}$ & $\begin{array}{l}\text { Stable angina, history of angina, MI } \\
\text { within } 3 \text { months, exercise test with ST } \\
\text { depression }>3 \text { mm, no previous PTCA }\end{array}$ & $\begin{array}{l}\text { Stenosis } \geqslant 70 \% \text { proximal two thirds, } \\
\text { no main artery stenosis }>50 \% \text {, no } 3 \\
\text { vessel disease }\end{array}$ & $2(69)$ & $\begin{array}{c}\text { CABG }(2 \%) ; \mathrm{Ml} \\
(0.01 \%) ; \text { non- } Q \text { wave } \\
\text { MI }(3.0 \%)\end{array}$ & 57 & 59 & NA & 66 & 2 \\
\hline $\begin{array}{l}\text { RITA-2 } \\
1997^{14}\end{array}$ & $\begin{array}{l}\text { Angina leading to admission within } 90 \\
\text { days, previous } Q \text { wave } M I \text {, no previous } \\
\text { PTCA, no left main stem disease }\end{array}$ & $\begin{array}{l}\text { Stenosis } \geqslant 50 \% \text { stenosis in two } \\
\text { projections or } 70 \% \text { stenosis in one } \\
\text { projection or occluded arteries }\end{array}$ & 1-3 (93) & $\begin{array}{c}\text { CABG }(1.4 \%) ; \mathrm{MI} \\
(1.4 \%) ; \text { death }(0.2 \%)\end{array}$ & 32 & 47 & NA & $\begin{array}{l}\text { Normal } \\
\text { function in } \\
54 \% \text { of } \\
\text { patients }\end{array}$ & 4 \\
\hline $\begin{array}{l}\text { AVERT } \\
1999^{15}\end{array}$ & $\begin{array}{l}\text { Angina or asymptomatic, } \mathrm{Ml} \text { or } \\
\text { unstable angina but not within } 14 \text { days, } \\
\text { no triple vessel disease }\end{array}$ & $\begin{array}{l}\text { Stenosis } \geqslant 50 \% \text { in one or two } \\
\text { vessels, no main artery stenosis }\end{array}$ & $2(99)$ & $\mathrm{MI}(0.5 \%)$ & 18 & & $43 \dagger$ & 61 & 4 \\
\hline
\end{tabular}

${ }^{\star}$ See methods section for details of scoring.

†Figure for MI and non-Q wave MI.

MI: myocardial infarction, CABG: coronary artery bypass graft; NA: not available. 


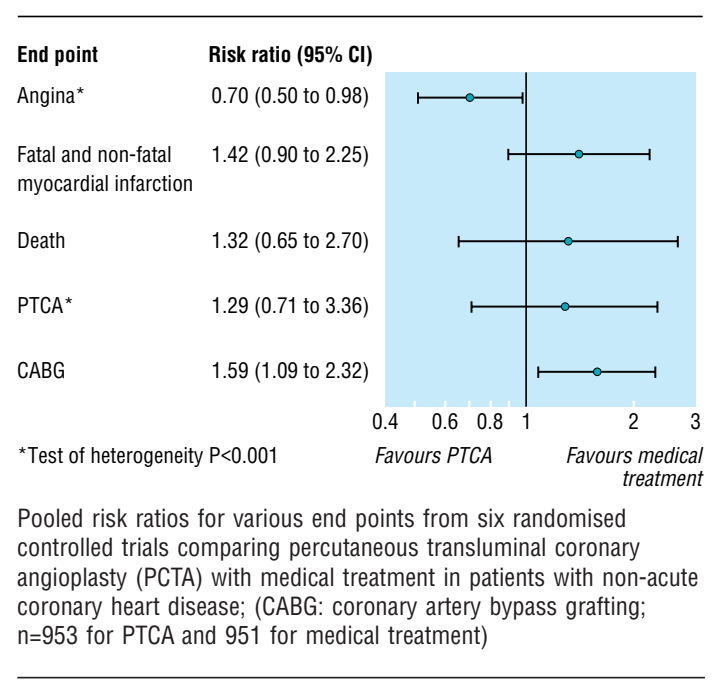

points. Low quality scores were mainly due to lack of concealment and documentation of blinded outcome assessment for clinical end points.

Table 2 provides information about event rates in single trials. The pooled risk ratio for angina in patients with percutaneous transluminal coronary angioplasty compared with medical treatment was $0.70(95 \%$ confidence interval 0.50 to 0.98 ), but there was significant heterogeneity $(\mathrm{P}<0.001)$ (figure). The pooled absolute risk difference for angina was $0.17(95 \%$ confidence interval 0.00 to 0.32 ; test of heterogeneity $\mathrm{P}<0.001$ ). The risk ratio for fatal and non-fatal myocardial infarction in patients treated with percutaneous transluminal coronary angioplasty compared with medical treatment was 1.42 ( 0.90 to 2.25 ; test of heterogeneity $\mathrm{P}>0.10$ ), and that for death was 1.32 (0.65 to 2.70; test of heterogeneity $\mathrm{P}>0.20)$. There was an increased risk of coronary artery bypass grafting (risk ratio $1.59 ; 1.09$ to 2.32; test of heterogeneity $\mathrm{P}>0.10)$ and an increased risk of repeated angioplasty $(1.29 ; 0.71$ to 3.36$)$, though the results for repeated angioplasty proved variable across studies (test of heterogeneity $\mathrm{P}<0.001$ ).

We explored heterogeneity and examined risk ratios and 95\% confidence intervals in trials with single versus multivessel percutaneous transluminal coronary angioplasty and trials with different quality scores ( $\leqslant 3$ or higher) and duration of follow up ( $\leqslant 24$ months or longer). For all end points (angina, death, myocardial infarction, coronary artery bypass grafting, and repeated percutaneous transluminal coronary angioplasty) we found similar summary estimates, and $P$ values for the difference in summary estimates in each pair of subgroups were all above 0.10 , indicating no significantly different effect sizes in subgroup summary estimates (data not shown).

\section{Discussion}

This systematic review suggests that percutaneous transluminal coronary angioplasty may be superior to medical treatment for the alleviation of angina in patients with non-acute coronary heart disease. We found large variability in results, however, with significant heterogeneity between trials, and the relatively small number of trials and patients resulted in wide confidence intervals around our pooled estimates. Thus, while these estimates suggest a reduction in relative risk for angina with percutaneous transluminal coronary angioplasty compared with medical treatment of $30 \%$, the $95 \%$ confidence interval includes a relative risk reduction of only $2 \%$ - that is, essentially no effect. This is also reflected in estimates of absolute risk difference: while our pooled estimate was an absolute difference of $17 \%$, the $95 \%$ confidence interval includes no difference at all.

\section{Exploration of heterogeneity}

If we consider the heterogeneity of results between trials our a priori hypotheses-inclusion of methodological quality of the trials, single versus multivessel disease, and duration of follow up-failed to explain the variability in the magnitude of the treatment effect; lack of power may account for this failure. Whatever the explanation, the differences in results suggest that the efficacy of percutaneous transluminal coronary angioplasty in relieving angina differs according to some characteristic of the patient or technique or skill of the cardiologist. Alternatively, some unknown feature of the study design or the measurement of angina may explain the differences in effect size.

Table 2 Number of clinical events and relative risks (95\% confidence intervals) for different end points in randomised controlled trials of percutaneous transluminal coronary angioplasty (PCTA) compared with medical treatment in non-acute coronary heart disease

\begin{tabular}{|c|c|c|c|}
\hline \multirow[b]{2}{*}{ End point and trial } & \multicolumn{2}{|c|}{ No with end point } & \multirow[b]{2}{*}{ Relative risk $(95 \% \mathrm{CI})$} \\
\hline & РCTA & Control group & \\
\hline \multicolumn{4}{|l|}{ Angina* $^{*}$} \\
\hline Parisi $1992^{17}$ & $44 / 105$ & $60 / 107$ & 0.75 (0.57 to 0.99$)$ \\
\hline Sievers $1993^{16}$ & $12 / 44$ & $12 / 44$ & 1.00 (0.51 to 1.95$)$ \\
\hline MASS $1995^{18}$ & $14 / 72$ & $49 / 72$ & 0.29 (0.18 to 0.48$)$ \\
\hline Folland $1997^{13}$ & $24 / 51$ & $32 / 50$ & 0.74 (0.52 to 1.05$)$ \\
\hline RITA-2 1997 ${ }^{14}$ & $375 / 504$ & $406 / 514$ & 0.94 (0.88 to 1.01$)$ \\
\hline \multicolumn{4}{|c|}{ Fatal and non-fatal MI } \\
\hline Parisi $1992^{17}$ & $5 / 105$ & $3 / 107$ & 1.69 (0.42 to 6.93$)$ \\
\hline Sievers $1993^{16}$ & $2 / 44$ & $1 / 44$ & 2.00 (0.19 to 21.26) \\
\hline MASS $1995^{18}$ & $2 / 72$ & $2 / 72$ & 1.00 (0.14 to 6.91$)$ \\
\hline Folland $1997^{13}$ & $2 / 51$ & $6 / 50$ & 0.33 (0.07 to 1.54$)$ \\
\hline RITA-2 $1997^{14}$ & $26 / 504$ & $13 / 514$ & 2.04 (1.06 to 3.92) \\
\hline AVERT $1999^{15}$ & $4 / 177$ & $4 / 164$ & $1.16(0.32$ to 4.24$)$ \\
\hline \multicolumn{4}{|l|}{ Death } \\
\hline Parisi $1992^{17}$ & $0 / 105$ & $1 / 107$ & 0.50 (0.01 to 14.89$)$ \\
\hline Sievers $1993^{16}$ & $0 / 44$ & $1 / 44$ & 0.50 (0.01 to 14.20$)$ \\
\hline MASS $1995^{18}$ & $1 / 72$ & 0/72 & 2.03 (0.07 to 59.51 ) \\
\hline Folland $1997^{13}$ & $2 / 51$ & $1 / 50$ & 1.96 (0.18 to 20.95$)$ \\
\hline RITA-2 $1997^{14}$ & $11 / 504$ & $7 / 514$ & $1.60(0.63$ to 4.10$)$ \\
\hline AVERT $1999^{15}$ & $1 / 177$ & $1 / 164$ & 0.92 (0.06 to 14.69$)$ \\
\hline \multicolumn{4}{|l|}{ Need for PCTA } \\
\hline Parisi $1992^{17}$ & $16 / 105$ & $11 / 107$ & 1.48 (0.72 to 3.04$)$ \\
\hline Sievers $1993^{16}$ & $5 / 44$ & $7 / 44$ & 0.71 (0.25 to 2.08$)$ \\
\hline MASS $1995^{18}$ & $27 / 72$ & $3 / 72$ & 9.00 (2.86 to 28.35$)$ \\
\hline Folland $1997^{13}$ & $11 / 51$ & $8 / 50$ & 1.35 (0.59 to 3.07$)$ \\
\hline RITA-2 $1997^{14}$ & $62 / 504$ & $101 / 514$ & 0.63 (0.47 to 0.84$)$ \\
\hline AVERT $1999^{15}$ & $18 / 177$ & $21 / 164$ & 1.08 (0.60 to 1.96$)$ \\
\hline \multicolumn{4}{|l|}{ CABG } \\
\hline Parisi $1992^{17}$ & $7 / 105$ & $0 / 107$ & 15.28 (0.88 to 264.00$)$ \\
\hline Sievers $1993^{16}$ & $2 / 44$ & $2 / 44$ & 1.00 (0.15 to 6.79$)$ \\
\hline MASS $1995^{18}$ & $8 / 72$ & $4 / 72$ & 2.00 (0.63 to 6.35$)$ \\
\hline Folland $1997^{13}$ & $3 / 51$ & $1 / 50$ & 2.94 (0.32 to 27.34$)$ \\
\hline RITA-2 1997 & $40 / 504$ & $30 / 514$ & 1.36 (0.86 to 2.15$)$ \\
\hline AVERT $1999^{15}$ & 9/177 & 2164 & $4.17(0.91$ to 19.01$)$ \\
\hline
\end{tabular}

${ }^{*}$ The AVERT study did not report number of patients with angina. CABG: coronary artery bypass graft. 
Much of the heterogeneity comes from the MASS trial, which showed a larger effect on angina and a greater need for repeat angioplasty than other studies. The MASS trial had an intermediate quality score and an intermediate follow up time compared with the remaining studies. ${ }^{18}$ At entry patients had only single vessel disease and the rate of complication was similar to that in other trials. We speculate that the differences may be due to the study having been conducted in a single centre with much experience. The cardiologists may be particularly skilled in their selection of patients or their surgical technique and particularly aggressive in their use of this form of angioplasty.

On the whole, the sample sizes of the studies were inadequate to estimate the effects on less common events. We found a trend indicating an increased risk from percutaneous transluminal coronary angioplasty for non-fatal myocardial infarction, death, and higher rates of repeated angioplasty, but the confidence intervals were wide, including the possibility of appreciable benefit. For coronary artery bypass grafting the confidence interval excluded no effect, suggesting a real increase in subsequent coronary artery bypass grafting in patients who undergo percutaneous transluminal coronary angioplasty.

\section{Limitations of study findings}

In addition to the limited power to find relevant treatment effects our review has other limitations. Although our comprehensive literature search makes it unlikely that we missed published trials, concern about publication bias remains. The relevance of publication bias in the current context is, however, questionable. Unpublished studies would probably have come from small centres with less experienced interventional cardiologists. ${ }^{19}$ As a result, the impact of percutaneous transluminal coronary angioplasty would, if anything, be less favourable than we found in the published studies and possibly inapplicable to results in larger centres with wider experience.

Patients included in these randomised trials were highly selected. Thus, generalisability of results from the studies to the general population of patients with non-acute coronary heart disease may be limited. While observational studies may be less prone to this problem they are open to patient selection biases that randomisation protects against (apparent benefits of percutaneous transluminal coronary angioplasty may be because of selection of patients with better prognosis for the procedure). The results of this meta-analysis are consistent with some of the largest observational studies that have compared care and outcomes in Canada and the United States. In these studies, compared with patients from Canada, patients from the United States had higher rates of percutaneous transluminal coronary angioplasty during the first 6 to 12 months after acute myocardial infarction, less angina, ${ }^{20}{ }^{21}$ and improved quality of life. ${ }^{22}$ In two studies investigators found no difference in survival, ${ }^{21}$ whereas in a third study survival in US patients undergoing more invasive procedures was better compared with that in Canadian patients. ${ }^{22}$ In two studies, however, the distinction between percutaneous transluminal coronary angioplasty and coronary artery bypass grafting was not made explicit, ${ }^{21}{ }^{22}$ and the superiority of invasive procedures could therefore be

\section{What is already known on this topic}

Percutaneous transluminal coronary angioplasty is increasingly used in the management of non-acute coronary disease

\section{What this study adds}

In non-acute coronary disease percutaneous transluminal coronary angioplasty may result in greater relief from angina than medical treatment, though the magnitude of effect varies considerably

The procedure may lead to an increase in coronary bypass grafting compared with medical treatment and is unlikely to reduce non-fatal myocardial infarction, death, or repeated angioplasty

The procedure should be use only in patients with non-acute coronary in whom angina cannot be controlled by medical treatment, though coronary artery bypass grafting is an alternative

related to a greater incidence of coronary artery bypass grafting, a finding consistent with the results of randomised trials.

The trials we summarised in this meta-analysis do not reflect important advances in the management of non-acute coronary heart disease over the past few years. Most trials did not make extensive use of stents for coronary angioplasty. There is growing evidence from randomised trials that patients treated with stents compared with conventional percutaneous transluminal coronary angioplasty have lower rates of restenosis and, as a consequence, fewer repeated angioplasties and less angina. ${ }^{23}{ }^{24}$ Whether the rate of myocardial infarction and death is reduced in patients undergoing angioplasty with stent implantation, however, has not been established.

Hydroxymethyl glutaryl coenzyme A (HMG-CoA) reductase inhibitors reduce morbidity and mortality in secondary prevention of coronary heart disease. ${ }^{25} 26$ Four of the six trials included in this analysis did not provide information on the use of lipid lowering drugs. In the RITA-2 trial only $13 \%$ of the patients were treated with lipid lowering drugs and no details were provided on the type of antilipidaemic drug. In the AVERT study patients randomised to medical treatment received an aggressive lipid lowering treatment with atorvastatin. ${ }^{15}$

\section{Conclusions}

In conclusion, this systematic review of randomised controlled trials suggests that percutaneous transluminal coronary angioplasty may lead to a reduction in angina in some patients with non-acute coronary heart disease, though the magnitude of the effect differs according to factors that we were not able to identify. The point estimates favouring medical treatment raise the possibility that percutaneous transluminal coronary angioplasty may increase myocardial infarction, mortality, or the need for further angioplasty, though the confidence intervals do not exclude small positive treatment effects. Percutaneous transluminal coronary angioplasty, as practised in these trials, increases the 
rate of coronary artery bypass grafting. One reasonable conclusion from these results would be that, particularly in the face of constraints on healthcare spending, clinicians should be restrained in their recommendations for percutaneous transluminal coronary angioplasty, reserving the procedure for patients whose symptoms of angina are not well controlled on medical treatment.

We thank Dr P Wolf for conducting the literature search and Professor Pocock and Dr Sievers for providing us with additional detailed study data.

Contributors: $\mathrm{HCB}$ initiated and coordinated the formulation of the primary study hypothesis, discussed core ideas, designed the protocol, and participated in the review and data abstraction process, analysis, and writing of the paper. $\mathrm{PH}$ initiated the research project, discussed core ideas, participated in the review and data abstraction process, was responsible for data entry and interpretation of the data, and contributed to the writing of the paper. CS did the data analysis, participated in the interpretation of data, and contributed to the writing of the paper. GHG discussed core ideas and participated in the interpretation of data and editing and writing of the paper. $\mathrm{HCB}$ is the guarantor.

Funding: None

Competing interests: None declared.

1 National Center for Health Statistics, Gillum BS, Graves EJ, Kozak KJ Trends in hospital utilization: United States, 1988-92. Washington, DC: Government Printing Office, 1996. (DHHS publication No (PHS) 96-1785. Series 13. No 124.)

2 Higginson LA, Cairns JA, Smith ER. Rates of cardiac catheterization, coronary angioplasty and coronary artery bypass surgery in Canada (1991). Can J Cardiol 1994;10:728-32.

3 Weaver WD, Simes RJ, Betriu A, Grines CL, Zijlstra F, Garcia E, et al. Comparison of primary coronary angioplasty and intravenous thrombolytic therapy for acute myocardial infarction: a quantitative review. JAMA 1997;278:2093-8.

4 Michels KB, Yusuf S. Does PTCA in acute myocardial infarction affect mortality and reinfarction rates? A quantitative overview (meta-analysis) of the randomized clinical trials. Circulation 1995;91:476-85.

5 Bates DW, Miller E, Bernstein SJ, Hauptman PJ, Leape LL. Coronary angiography and angioplasty after acute myocardial infarction. An Intern Med 1997;126:539-50.

6 Solomon AJ, Gersh BJ. Management of chronic stable angina: medica therapy, percutaneous transluminal coronary angioplasty, and coronary artery bypass graft surgery. Lessons from the randomized trials. An Intern Med 1998;128.216-29.

7 Anderson WD, King SB. A review of randomized trials comparing coronary angioplasty and bypass grafting. Curr Opin Cardiol 1996;11:583-90.

8 Jadad AR, Moore RA, Jenkinson C, Reynolds DJ, Gavagahn DJ. Assessing the quality of reports of randomized clinical trials: is blinding necessary? Cont Clin Trials 1996;17:1-12.

9 DerSimonian R, Laird N. Meta-analysis in clinical trials. Contr Clin Trials $1986 ; 7: 177-88$

10 Fleiss JL The statistical basis of meta-analysis. Stat Meth Med Res $1993 \cdot 9 \cdot 121$
11 Madsen JK, Grande P, Saunamäki K, Thayssen P, Kassis E, Eriksen U, et al. Danish multicenter randomized study of invasive versus conservative treatment in patients with inducible ischemia after thrombolysis in acute myocardial infarction (DANAMI). Danish trial in acute myocardia infarction. Circulation 1997;96:748-55.

12 Rogers WJ, Bourassa MG, Andrews TC, Bertolet BD, Blumenthal RS, Chaitman BR, et al. Asymptomatic cardiac ischemia pilot (ACIP) study: outcome at 1 year for patients with asymptomatic cardiac ischemia randomized to medical therapy or revascularization. The ACIP investigators. Am Coll Cardiol 1995;26:594-605.

13 Folland ED, Hartigan PM, Parisi AF. Percutaneous transluminal coronary angioplasty versus medical therapy for stable angina pectoris: outcomes for patients with double-vessel versus single-vessel coronary artery disease in a veterans affairs cooperative randomized trial. Veterans affairs ACME investigators. J Am Coll Cardiol 1997;29:1505-11.

14 RITA-2 trial participants. Coronary angioplasty versus medical therapy for angina: the second randomised intervention treatment of angina (RITA-2) trial. Lancet 1997;350:461-8.

15 Pitt B, Waters D, Brown WV, van Boven AJ, Schwartz L, Title LM, et al. Aggressive lipid-lowering therapy compared with angioplasty in stable coronary artery disease. Atorvastatin versus revascularization treatment investigators. N Engl J Med 1999;341:70-6

16 Sievers B, Hamm CW, Herzner A, Kuck KH. Medical therapy versus PTCA: a prospective, randomized trial in patients with asymptomatic coronary single-vessel disease [abstract]. Circulation 1993;88(I):297.

17 Parisi AF, Folland ED, Hartigan P. A comparison of angioplasty with medical therapy in the treatment of single-vessel coronary artery disease. Veterans affairs ACME investigators. N Engl J Med 1992;326:10-6.

18 Hueb WA, Bellotti G, de Oliveira SA, Arie S, de Albuquerque CP, Jatene $\mathrm{AD}$, et al. The medicine, angioplasty or surgery study (MASS): a prospective, randomized trial of medical therapy, balloon angioplasty or bypass surgery for single proximal left anterior descending artery stenoses. $J \mathrm{Am}$ Coll Cardiol 1995;26:1600-5.

19 Shook TL, Sun GW, Burstein S, Eisenhauer AC, Matthews RV. Comparison of percutaneous transluminal coronary angioplasty outcome and hospital costs for low-volume and high-volume operators. Am J Cardiol 1996;77:331-6.

$20 \mathrm{Tu}$ JV, Pashos CL, Naylor CD, Chen E, Normand SL, Newhouse JP, et al. Use of cardiac procedures and outcomes in elderly patients with myocardial infarction in the United States and Canada. $N$ Engl J Med 1997;336:1500-5

21 Rouleau JL, Moye LA, Pfeffer MA, Arnold JM, Bernstein V, Cuddy TE, et al. A comparison of management patterns after acute myocardial infarction in Canada and the United States. The SAVE investigators. $N$ Engl J Med 1993;328:779-84

22 Mark DB, Naylor CD, Hlatky MA, Califf RM, Topol EJ, Granger CB, et al Use of medical resources and quality of life after acute myocardial infarction in Canada and the United States. N Engl J Med 1994;331:1130-5.

23 Versaci F, Gaspardone A, Tomai F, Crea F, Chiariello L, Gioffre PA. A comparison of coronary-artery stenting with angioplasty for isolated stenosis of the proximal left anterior descending coronary artery. $N \mathrm{Engl}$ Med 1997;336:817-22.

24 Macaya C, Serruys PW, Ruygrok P, Suryapranata H, Mast G, Klugmann S, et al. Continued benefit of coronary stenting versus balloon angioplasty: one-year clinical follow-up of Benestent trial. Benestent study group. $J A m$ Coll Cardiol 1996;27:255-61.

25 Scandinavian Simvastatin Survival Study Group. Randomised trial of cholesterol lowering in 4444 patients with coronary heart disease: the Scandinavian simvastatin survival study (4S). Lancet 1994;344:1383-9.

26 The long-term intervention with pravastatin in ischemic disease (LIPID) study group. Prevention of cardiovascular events and death with pravastatin in patients with coronary heart disease and broad range of initial cholesterol levels. N Engl J Med 1998;339:1349-57.

(Accepted 20 March 2000)
Until recently, the English language lacked a single, punchy, positively flavoured noun to describe a medicine's (greater or lesser) freedom from side effects. Whereas German has its Verträglichkeit (from sich vertragen - to agree with something or someone), a word that emphasises the positive aspect of something being well tolerated, all that could be found in English was more or less verbose phraseology, such as a good side effect profile, without any irritant effect, etc, invariably dragging in the idea of something adverse-not only clumsy, but, surely, a pharmaceutical copywriter's nightmare. Quite obviously, this was a void that needed filling.

And filled it has been, to a large extent, by the adoption, over the last 10 years or so, of tolerability (a term used, in non-pharmaceutical contexts, since at least 1640). While a copywriter would still be extremely ill advised to describe a firm's new wonder drug as tolerable (remember the Thurber dinner party: "This claret is really quite tolerable considering it cost only $\$ 2$ a bottle"?), to say that it has tolerability is now okay. In fact, this acceptance goes beyond the realm of advertising: a trawl through the $B M J$ on the internet (January 1996 to May 1999) produced 10 instances of the use of tolerability in titles or abstracts, and 53 in papers (plus one isolated hit on the less euphonious and no more justifiable tolerableness). The incidence would have been even higher had the use of the term in advertisements, over the same period of time, been factored in. No doubt, some purists will still jib at this usage. However, tolerability, it seems, is here to stay. It may not be ideal, but it will do-tolerably well.

Karin R M Band and David Winstanley freelance medical translators, Brentwood, Essex

We welcome articles of up to 600 words on topics such as A memorable patient, A paper that changed my practice, My most unfortunate mistake, or any other piece conveying instruction, pathos, or humour. If possible the article should be supplied on a disk. Permission is needed from the patient or a relative if an identifiable patient is referred to. 